\title{
Doctors top list of worst drivers for fifth straight year
}

Cite as: CMAJ 2018 July 23;190:E896-7. doi: 10.1503/cmaj.109-5632

Posted on cmajnews.com on July 6, 2018.

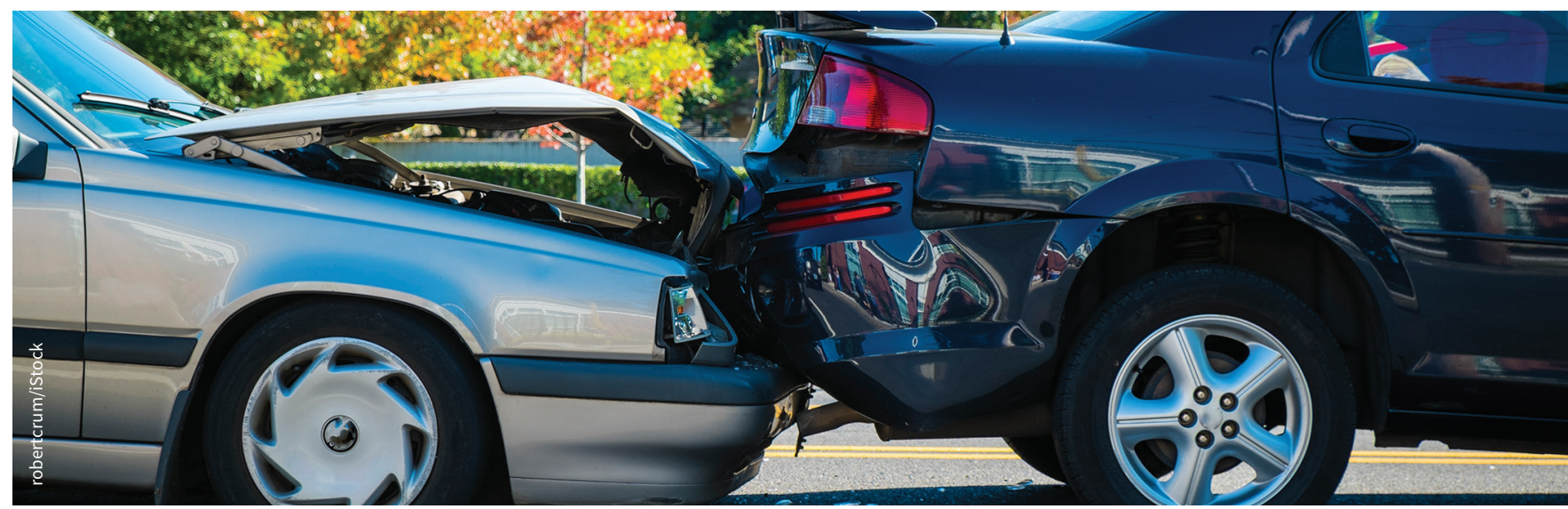

Stress and fatigue have been cited as reasons for high rates of traffic collisions among health care professionals.

ast year in the United Kingdom, general practitioners made the most insurance claims for motor vehicle collisions in which they were at fault of any profession, according to new research by GoCompare Car Insurance. About 1 in 8, or $12.4 \%$ of all GPs in the UK, made at least one at-fault claim. It was the fifth year in a row that GPs took the number one position. The national average for at-fault claims across all professions is about $6 \%$. Other health care professionals dominated the top of the list, including hospital consultants $(11.5 \%)$, hospital doctors $(10.7 \%)$ and surgeons (10.4\%).

According to Matt Oliver, a spokesperson for GoCompare, these professions "are all roles which carry a significant degree of stress and usually long hours, potentially leading to a lack of concentration on the road."

GoCompare has conducted this research for several years, and doctors and other health professionals consistently rank among the most accidentprone professions. In 2014, the company found that $28.6 \%$ of GPs had made a car insurance claim during the previous five years. Clinical psychologists were also high on the list (25\%), as were dental surgeons $(23.9 \%)$, community nurses $(23.6 \%)$ and hospital managers (23.4\%). Overall, health care professionals accounted for $75 \%$ of the top 20 positions.

A separate analysis of two million insurance claims in the UK, conducted by Moneysupermarket, a financial services company that compares insurance rates, also found GPs and surgeons to be involved in the most traffic crashes. It found that 361 of every 1000 surgeons had made an at-fault insurance claim over the past five years. The only nonhealth care occupation in the top 10 was probation officer.

However, most collisions involving GPs are minor; they did not make the top 20 for accident claims involving injury in the most recent GoCompare study. As noted in 2014 by Andrew Smith, who studies occupational and health psychology at Cardiff University in the UK, stress can make you "absent minded when it comes to day-today activities and find it difficult to concentrate on tasks," but "the types of accidents that are attributed to stress tend to be rel- atively minor bumps, caused by lapses in concentration whilst driving."

Another theory on why health care professionals are involved in so many collisions, put forth by Craig Knight, an expert on the psychology of working environments, is that they carry a "significantly raised degree of cognitive load" and "making decisions that will affect somebody's chances of sustained wellbeing or survival" can lead to distraction when performing other tasks, such as driving. Knight also noted that health professionals work every day with patients who are also under stress, and "stress has a level of contagion which doesn't help with concentration."

The problem of fender-bender physicians is not limited to the UK. In 2004 in the United States, Quality Planning Corporation, a company that helps insurance brokers rate driver risk, found that doctors ranked second in vehicular collisions. The only people who fared worse were young students, often in their teens, who lacked driving experience. The company examined insurance data on one million drivers over an 18-month period. It found 
that $11 \%$ of physicians were involved in accidents. The figure for farmers, by contrast, was $4 \%$. Of the 40 occupations ranked, the least likely to be in motor vehicle accidents were politicians, pilots, firemen and farmers.

Medical residents, who may have the most grueling work schedules in all of medicine, have also been found to be involved in high rates of motor vehicle incidents. A 2012 study of medical residents at
Mayo Clinic in Minnesota found that 56\% had been involved in motor vehicle incidents during their residencies, $11.3 \%$ had been in collisions, and $43.3 \%$ reported near-miss motor vehicle crashes. "Our results confirm the importance of fatigue and sleepiness to resident safety concerns," the authors concluded. "In addition, higher levels of distress may be contributory factors to motor vehicle crashes and other related incidents."
Data out of the UK about junior doctors found similar results. A 2017 survey of anesthesia trainees in the UK found that $57 \%$ had experienced a motor vehicle accident or a near-miss when driving home after night shifts. The problem was attributed, in part, to fatigue that resulted from an absence of breaks during shifts and inadequate rest facilities.

Roger Collier, CMAJ 